\title{
A!
}

This is an electronic reprint of the original article.

This reprint may differ from the original in pagination and typographic detail.

Diaz-Kommonen, Lily

\section{Interactive Diorama}

Published in:

International Symposium on Mixed and Augmented Reality

DOI:

10.1109/ISMAR-Adjunct.2017.85

Published: 13/10/2017

Document Version

Peer reviewed version

Please cite the original version:

Diaz-Kommonen, L. (2017). Interactive Diorama: A Virtual Reality (VR) Reconstruction of The Anatomy Lesson of Doctor Nicolaes Tulp by Rembrandt, 1632. In International Symposium on Mixed and Augmented Reality: ISMAR 2017, Adjunct Proceedings (pp. 258-261). IEEE. https://doi.org/10.1109/ISMAR-Adjunct.2017.85

This material is protected by copyright and other intellectual property rights, and duplication or sale of all or part of any of the repository collections is not permitted, except that material may be duplicated by you for your research use or educational purposes in electronic or print form. You must obtain permission for any other use. Electronic or print copies may not be offered, whether for sale or otherwise to anyone who is not an authorised user. 


\title{
Interactive Diorama: A virtual reality (VR) reconstruction of The Anatomy Lesson of Doctor Nicolaes Tulp by Rembrandt, 1632
}

\author{
Lily Díaz-Kommonen \\ Aalto University, School of Arts, Design and Architecture
}

\begin{abstract}
This document describes some aspects of a design and research project undertaken during the years 20132017 by the Systems of Representation research group in the Department of Media at Aalto University in Finland. The objective of the work has been to create an interactive diorama based on the painting The Anatomy Lesson of Dr. Nicolaes Tulp. The diorama concept comprises a virtual reality simulation of the artwork in which several of the characters in the painting are re-created as 3D avatars and combined with other audiovisual media including sound and video. Using the HTC-Vive virtual reality system as interface, it is possible for a guest in an exhibition to extent enter the space of the painting itself and to interact with the characters. It is intended that the diorama will be displayed in diverse venues and to a large variety of audiences. This implies a challenge for which there is a need to develop new design knowledge. In this essay I argue that information architecture (IA) can be used in the structuring of user experience as well as in the organizing and management of contents.
\end{abstract}

Keywords: Digital cultural heritage, information architecture, media arts, virtual reality.

Index Terms: [Human-centered computing]: Interaction paradigms: Virtual reality; [Arts and humanities] Media arts.

\section{INTRODUCTION}

The Anatomy Lesson of Dr. Nicolaes Tulp, is a $17^{\text {th }}$ century oil painting by Rembrandt that depicts a human dissection directed by the famed surgeon and mayor of Amsterdam. In our work, using human-centered design methods in the Systems of Representation research groups at Aalto University we have created a simulation that uses virtual reality to allow a visitor to actively survey a hypothetical reconstruction of the space and the lesson depicted in Rembrandt's painting. The virtual anatomy theater was created using $18^{\text {th }}$ century visual sources in combination with photogrammetry documentation done on site at Waag Society in Amsterdam.

In addition to being part of the art canon of Western art the $169.5 \times 216.5 \mathrm{~cm}$ oil painting is an intriguing artifact that has been the subject of diverse replicas that have enabled a variety of interpretive readings and re-readings. Beginning with the recent 2010 appropriation by
Zimbabwean artist Yiull Damaso in which Nelson Mandela's body substitutes the original corpse of Aris Kindt, a criminal whose remains were the subject of the January 16, 1632 autopsy; to its use as a rhetorical aid representing an eternal present in W.G. Sebald's The Rings of Saturn; and going back to include Edouard Manet's 1856 copy, the painting provides a singular opportunity to create a unique, dialogical, mixed reality experience.

In our view the painting can also be regarded as commentary about the relationship between scientific knowledge and spectacle. Our interactive media art installation seeks to continue the dialogue and hopefully contribute to the discourses generated by this object of heritage.

\section{NeW KNOWLEDge AND PRACTICES, NEW ART AND DESIGN OBJECTS}

During the past two decades our ubiquitous use of computers has precipitated changes in our cultural developments and dynamics. New fields of knowledge and practices have emerged. This has been the case in the sciences, the humanities and also in art and design. In its use of the latest trends in virtual reality technology Interactive Diorama is an example of a different class of digitally born art and design object that blends the temporal aspects of cinema with the immersive, spatially situated, and embodied interaction only possible through the use of virtual reality.

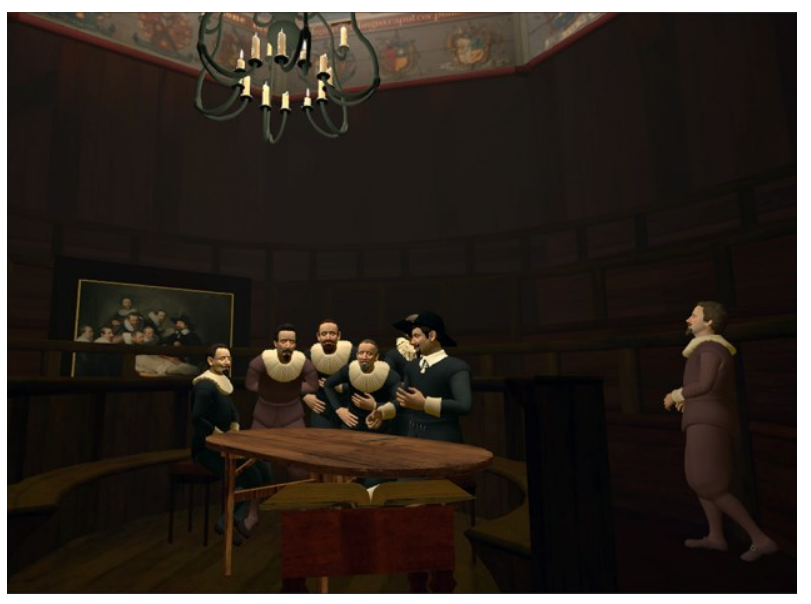

Figure 1: Interactive Diorama of the Anatomy Lesson of Dr. Nicolaes Tulp is a simulation that reconstructs the space of the anatomy theater in which the lesson supposedly took place. 
The objective in building such installation has been to explore the topic of the design of historical simulations from the point of view of it being a continuum ranging from the most accurate and equivalent simulation to the most artistic and interpretive rendition. as can be appreciated in Figure 1, Interactive Diorama is a single channel installation where an interactant navigates through the virtual anatomy theater. Initially, an audio-visual narrative provides the opportunity of learning to use the navigation control tools and also guides the visitor through some of the themes implicit in the canvass. This narrative is the subject dealt with in the interactive matrix timeline visualization. A section of the timeline is presented in Figure 3. Among these topics that have been thoroughly researched by art historians that are included are the promotion of the institution of the guild and its members each of whom paid a fee to be included in the painting, the acquisition and advancement of scientific knowledge, and the affirmation of the religious ethos in $17^{\text {th }}$ century Netherlands.

In addition to the audio-visual narrative encountered at the beginning of the experience, the visitor can freely interact with virtual objects such as the book that delivers a contemporary day anatomy lesson in video, or the scissors lying on the table. She or he can use teleport feature in Vive's interface to jump throughout the stands of the anatomy theatre. The painted murals of the coat-of-arms of the surgeons, and the chandelier with lit candles can be appreciated by surveying the domed ceiling of the room. Simultaneously it is also possible for an audience to vicariously experience the installation, through the broadcast of the user's engagement in the virtual space, that using video and sound is transmitted to the general exhibition space.

\subsection{Bringing the body into information space}

The topic of engagement as an immersed and embodied entity with agency (as in being surrounded by a different reality that one can affect) is one of the key aspects that differentiate virtual reality from the traditional cinema experience. The combined use of immersion with simulation can effectively extend the impact of the narrative in traditional genres such as documentary and fiction drama. This might be one of the reasons behind film director Alejandro Iñárritu's statement that "virtual reality is a wholly different medium, posing different theoretical and narrative challenges." [1]

Already there are several techniques emerging and it is important to distinguish between them. There is the 360-degree panorama stereoscopic film technique that relies on the use of the proscenium paradigm whereby content is delivered to the audience through projections on to a two-dimensional surface. Then there is also the fully immersive paradigm where the body is placed, and tracked through the use of sensors, in a three-dimensional computer-generated environment. It is this later method that we have used in our reconstruction.

We have found that the freedom of movement within a truly three-dimensional virtual space for example, can make it particularly difficult to implement the type of rhetorical elements traditionally used in genres such as film. Introductory graphics, title sequences, text captions and visual transitions for example, are extremely difficult to render in situations where the user can decide to look and move anywhere at any time. Though new products keep emerging HTC Vive recently announced eye-tracking capabilities for their head mounted displays there is still a need to better understand ways of supporting the type of natural interaction and spatial navigation that humans have acquired through thousands of years of evolution. It also takes into account both the allocentric wayfinding that relies on external cues from the environment as well as the egocentric and dynamic responses emerging via natural interaction and embodied knowledge. [2]

\subsection{Information architecture}

Information architecture is an area of knowledge that emerged during the past few decades to a large extent as a response to the increasing presence and intensified use of information environments such as the World Wide Web in everyday human activities. While generally identified as related to the organization of knowledge in digital archives, information repositories and websites, information architecture is also concerned with providing frameworks that enable not just access but also the understanding of information. [3] This later characteristic involves the ability to properly contextualize the data so that it can be accurately interpreted. Thus it is not simply serving the data morsel but also bringing along related information chunks that contribute to making the aforementioned into savoury and meaningful patterns (e.g knowledge).

In general, information communication technology has been very successful in delivering accurate data. However, being able to retrieve the right data in the proper context is still very much an issue of serious concern. Already in 1989 Saul Wurman described the situation as one of emerging information anxiety fueled by an inability to bridge the growing gap between data and knowledge. [4] In 1996, he proposed LATCH as acronym for the five pertinent criteria of Location, Alphabet, Time, Category and Hierarchy, through which to organize information. [5] These are not new information organization techniques. From an information visualization viewpoint, Lima for example has cogently presented the use of hierarchy, location and time as organizing principles used in printed media throughout history. [6] Kahn, Lenk and Kackmarek's cartography informed approach has also brought together the realm of printed media with online virtual repositories. They have adapted 
and further developed techniques for the visual ordering of information space via the use of isometric map perspectives found in $18^{\text {th }}$ century maps. [7] Morville who with Rosenfeld was an early contributor to the field has linked the notion of IA with human activity in physical space through his notion ambient findability. He defined this as the capacity for a system or environment to support navigation and discovery. $[3,8]$

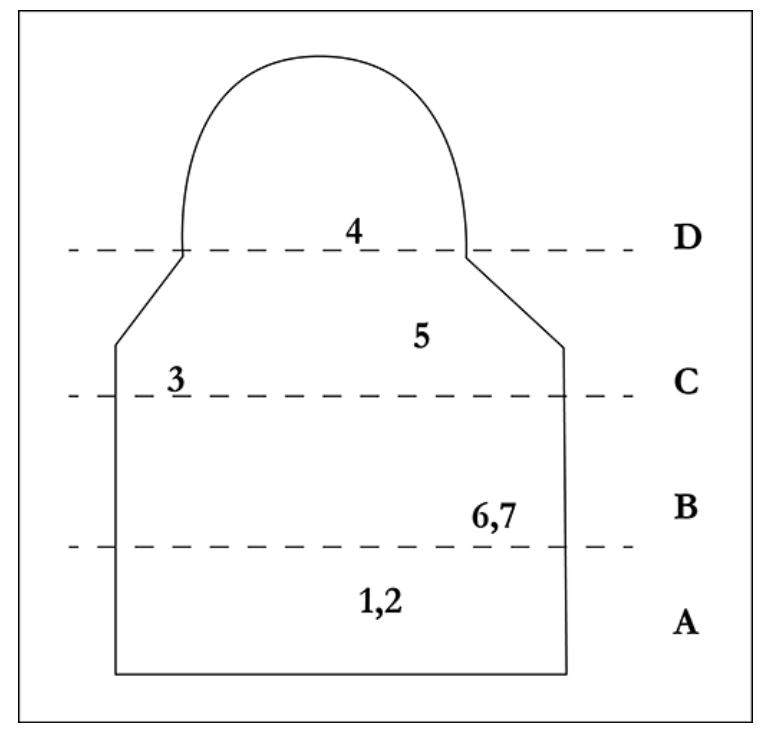

Figure 2: Front $(x, y)$ view of Planning Diagram for Rembrandt installation information architecture. The letters indicate levels, or layers, where content can be placed throughout the space and shown at different points in time. The numbers indicate seven captions that have been inserted into the virtual space.

Although the works cited have primarily focused on IA for online screen-based information environments, I believe that their emphasis on spatial interaction (rather than text) is significant in how it brings together the natural embodied way of human interaction with computer mediated communications systems. Thus, it is my contention that IA can be used in the design for virtual reality.

\subsection{Planning diagram and interaction matrix}

A generalized explanation about the best way to design and implement IAs for complex VR sites is a topic that will need additional time for research and study. In this essay I limit myself to describing the IA we have used to design an installation such as the Interactive Diorama. In this case, the IA consists of two information graphic representations that aim to include all the components involved in the participant's interaction and experience. These graphics are: 1 . a planning diagram and 2 . an interaction matrix.

To the extent that we use our eyes and our bodies, navigating a virtual space bears some similarities with finding our way around in real space: We make assumptions based on our knowledge of the real world and we learn from experience when it does not meet our expectations. Thus, in the Interactive Diorama Rembrandt installation, the planning diagram is a sketch that replicates the basic physical form of the original site as it has been recreated in the virtual space. The diagram in Figure 2 depicts a frontal $(x, y)$ view of the site showing how it was divided into four levels. The virtual space was partitioned into these levels, in order to organize the user experience in accordance to the audio-visual narrative created. The levels were also used to structure the navigation in relation to the virtual objects contained, such as the anatomy table, the theatre stands, a chandelier, and a book, as well as the seven doctors.

The audio-visual narrative serves the purpose of teaching the user the proper use of the system. However, it also tells the story of basic events related to the making of the painting. Upon entering the virtual space in the same position of the deceased inmate, one is informed of how the body of a recently executed criminal was used for the dissection. When one moves away from the operating table and upwards towards the stands, liturgical music is heard.

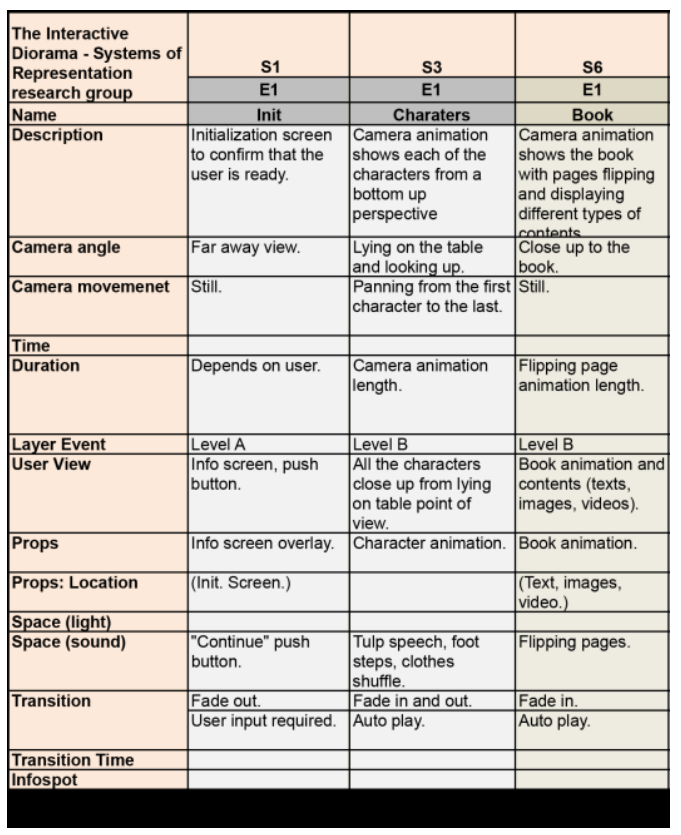

Figure 3: An edited view of the Interaction matrix for Ithe Interactive Diorama project. The figure shows the first three episodes in scenes one, three and six.

Text captions with information about the religious and civic aspects of the event appear as one ascends further to explore the upper levels, such as the cupola, where the coat-of-arms of the guild's members are depicted. Back on the first level as one stands in front of the table we are further informed how each of the members paid to be 
included and that the book used for the lesson was probably Andrea Veselius 1543 De humanis corporis fabrica.

Once the narrative is over it is possible to roam the space freely. Nevertheless the levels proved to be useful in how they allowed the producer and the software developer to track and manage the use of information assets. As distinct from film where a pre-rendered experience is tendered to the spectator, in VR the user is part of the environment. Thus the structuring of the passing of time in relation to the user experience becomes a bigger issue. When are the doctors moving, or speaking? What happens when we select the book? How do we learn who were these people? These are some of the things that are available through free exploration but which are not directly addressed in the narrative.

Planning diagrams need not be limited to already existing physical spaces but can also be designed to accommodate imaginary spaces and landscapes. A vital condition however is that the actual dimensions in which embodied interaction is possible should be depicted in the diagram. Once such information representation is put to use, it assumes the role of implicit structure.

As is shown in Figure 3, the interaction matrix is an information representation graphic in the form of a timeline sequence that aims to map the state of the entities in the system in time. It includes the input data, the tools used at every instance to launch and process it, the possible modes of interaction with the data itself as well as the output resulting from such exchanges. All of the project's assets are organized in relation to the audio-visual narrative encountered at the beginning of the experience. The narrative itself is further broken down into Scenes and Episodes. The objective is to ensure deep integration between all of the elements and levels that are realized in the work. [9] In this manner it bears more of a resemblance with traditional dramaturgical description such as the Dispozione Scenica used in Italian opera, than with other methods developed for user studies, such as task analysis or task flow diagrams.

The matrix further allows for a sub-division of the user experience into time instances that are assigned a location. Thus the producer, the software developer and other team members can track the interaction location, user view, if there are additional content assets such as video or text, an event's duration as well as the transition to the next event.

\section{Discussion}

By bringing a better understanding of ongoing processes and existing assets, it could be argued that instruments such as the ones described can enable better organization throughout the design and production processes of complex information representation objects. This might have a bearing in creating a better user experience. Nevertheless there is still much work to be done to arrive at a satisfactory description of what constitutes the information architecture of a virtual reality space.

For example, from a knowledge management perspective it could be said that the 'place' created in the painting is more than the painting itself, since that which is illustrated in the artwork has slowly come into being as layer upon layer of artistic, historical, and scientific discourse is aggregated. Thus the painting is part of knowledge networks dealing with European artistic and scientific exploration.

From the technical viewpoint, the analytic categories are heavily influenced by the use of the Unity 3D as authoring tool. Could the list of key components related to the work done with user interaction in virtual reality be created so that it applies to all cases regardless of which platform is used for programming? Is the hierarchy of categories that we are using the best or is there a way in which we could show how the information in the categories becomes unified from episodes into events within the narrative? Are there visualization tools that could be used to apprehend all the contents?

\section{Conclusion}

Currently the space of the Interactive Diorama installation is not shared and there is only one possible interaction channel enabled. We would like to extend the interaction to include other embodied users in the virtual space and in the future perhaps enable Internet access. These developments however will raise the level of technical complexity. At the moment our objectives are primarily to research, analyze and better understand the nature of the virtual space itself as well as how to design the human interaction and experience within.

\section{REFERENCES}

[1] J. Farago. Iñárritu's ‘Carne y Arena’ Virtual Reality Simulates a Harrowing Border Trek, The New York Times, May 17, 2017.

[2] P. Morville. Ambient Findability, O’Reilly, 2005.

[3] N. Davis. "Transforming Our Conversation of Information Architecture with Structure", Bulletin of the Association for Information Science and Technology-June/July 2013 -Volume 39, Number 5.

[4] S.R. Wurman. Information Anxiety, Doubleday Press, 1989.

[5] M. Lima. Visual Complexity

[6] S.R. Wurman. Information Architects, Graphis Press, 1996.

[7] P. Kahn, K. Lenk, P. Kackmarek. Mapping Websites: Digital Media Design, Rotovision Press, 2001

[8] P. Morville, L. Rosenfeld. Information Architecture, 2008.

[9] M.L. Ryan. Peeling the onion: Layers of interactivity in digital narrative texts. Based on talk presented at the Interactivity of 
Digital Texts conference held in Munster, Germany, May 2005.

Retrieved from, http://www.marilaur.info/onion.htm.

[10] 